
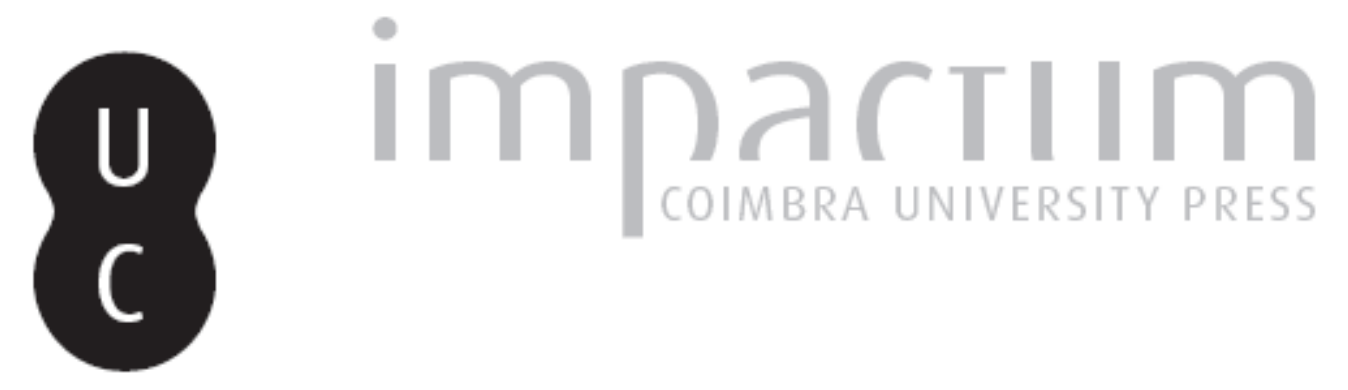

\title{
[Recensão a] Juan L. GARCíA ALONSO, La Península Ibérica en la Geografía de Claudio Ptolomeo
}

\author{
Autor(es): $\quad$ Guerra, Amílcar
}

Publicado por: Faculdade de Letras da Universidade de Coimbra

URL persistente:

URI:http://hdl.handle.net/10316.2/37715

DOI:

DOI:http://dx.doi.org/10.14195/1647-8657_43_17

Accessed : $\quad$ 26-Apr-2023 13:27:52

A navegação consulta e descarregamento dos títulos inseridos nas Bibliotecas Digitais UC Digitalis, UC Pombalina e UC Impactum, pressupõem a aceitação plena e sem reservas dos Termos e Condições de Uso destas Bibliotecas Digitais, disponíveis em https://digitalis.uc.pt/pt-pt/termos.

Conforme exposto nos referidos Termos e Condições de Uso, o descarregamento de títulos de acesso restrito requer uma licença válida de autorização devendo o utilizador aceder ao(s) documento(s) a partir de um endereço de IP da instituição detentora da supramencionada licença.

Ao utilizador é apenas permitido o descarregamento para uso pessoal, pelo que o emprego do(s) título(s) descarregado(s) para outro fim, designadamente comercial, carece de autorização do respetivo autor ou editor da obra.

Na medida em que todas as obras da UC Digitalis se encontram protegidas pelo Código do Direito de Autor e Direitos Conexos e demais legislação aplicável, toda a cópia, parcial ou total, deste documento, nos casos em que é legalmente admitida, deverá conter ou fazer-se acompanhar por este aviso.

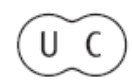


CONIMBRIGA

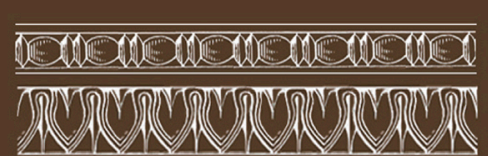

INSTITUTO DE ARQUEOLOGIA

VOLUME XLIII - 2004

FACULDADE DE LETRA

UNIVERSIDADE DE COIMBRA 
percute-se também na facilidade com que para aí são carreados palavras e outros dados, acompanhados das respectivas notações epigráficas, reflectindo a leitura que realmente é possível realizar a partir do monumento. São também dignas de nota as tábuas de concordâncias que primam por não visarem apenas os grandes corpora e repertórios epigráficos, mas incluem todas as restantes obras e revistas em que se publicou o material epigráfico, além da concordância com a base de dados PETRAE.

A edição é de qualidade, em papel couché, no qual ressaltam as excelentes fotografias a preto e branco incluídas nas treze estampas que fecham o volume, e encadernação cartonada, com gravações prateadas, protegida por elegante sobrecapa negra acometida por caracteres brancos e ilustrada com fotografia a cores de uma das inscrições na portada.

A minúcia e o rigor científico postos na elaboração deste corpus epigráfico regional fazem dele um instrumento de trabalho fiável para epigrafistas e historiadores da Antiguidade, mas não será menos útil como repositório de informação para todos os amantes da História do seu cantão que a procurem nos capítulos de síntese (introdução e conclusões), já que o catálogo é eminentemente técnico, respondendo aos objectivos da publicação e da colecção em que se insere.

Armando Redentor

Juan L. García Alonso, La Península Ibérica en la Geografía de Claudio Ptolomeo, (Anejos Veleia, Series minor 19), Universidad del Pais Vasco / Euskal Herriko Unibertsitatea, Vitoria/Gasteiz, 2003. 562 p., ISBN: 84-8373-569-5.

A atenção dada aos autores clássicos e a importância atribuída às informações que estes nos legaram continua a ser um dos aspectos que parece marcar a investigação sobre a antiguidade peninsular. Apesar da vasta panóplia de estudos que recorrem, de forma mais ou menos sistemática, aos dados dos autores de língua grega e latina, é evidente que se justifica e impõe uma investigação profunda sobre estes materiais, especialmente no domínio da interpretação e análise das suas informações. Têm sempre lugar, na minha perspectiva, as boas edições ou os comentários rigorosos e diversificados sobre esse amplo repertório literário. Por essa razão, considero de toda a pertinência a publicação deste contributo sobre a Geografia de Ptolomeu, na parte que se refere à Península Ibérica.

Tendo como ponto de partida um trabalho académico (1993) sobre cuja redacção passou mais de uma década e depois de ter sido disponibilizado em microfichas (1995), edita-se agora esta obra fundamental, após uma actualização justificada por novos contributos entretanto vindos à luz nos domínios da toponímia e da 
geografia antiga. Entre estes, diga-se, se contam alguns artigos do próprio autor relativos à análise de aspectos particulares dos dados de Ptolomeu.

Só por esta razão, haveria já bons motivos para saudar o aparecimento da obra. Mas, no caso vertente, há ainda razões acrescidas para tal. De facto, como se sublinha na Introdução (p. 13-14), a Geografia conheceu até ao momento um número muito reduzido de edições críticas e também elas se encontram actualmente a reclamar uma aturada revisão. Esta circunstância era particularmente sentida no que respeitava à Península Ibérica, em relação à qual a edição de Müller (1883) continuava a ser a base de trabalho. No entanto, muitos autores puseram em evidência as suas insuficiências. Por outro lado, a edição que poderia apresentar-se como uma alternativa, a Nobbe, datada de 1843-1845, não possui qualquer aparato crítico e evidencia limitações idênticas às de Müller. Não se trata tanto de serem textos estabelecidos há muito tempo, mas de assentarem num leque de manuscritos hoje substancialmente acrescentado, nalguns casos com códices primários que representam uma importante tradição.

Por isso, um dos méritos mais salientes desta publicação reside precisamente no facto de se propor, como trabalho de base, cotejar os principais manuscritos como meio de chegar a um texto o mais fiável possível. Na realidade, ainda que a obra não tenha sido pensada como uma edição crítica da parte hispânica da Geografia, o resultado traduz-se, desde logo, na apresentação do texto correspondente à Ibéria (falta apenas a indicação das coordenadas dos elencos das cidades), com a fixação do repertório onomástico da obra, cujas formas decorrem de uma avaliação da mais importante tradição manuscrita. Trata-se, pois, de um inestimável trabalho de crítica textual, de que esta importante fonte para a geografia antiga peninsular estava tão carecida.

Para um usuário das fontes clássicas, todavia, apresenta o inconveniente de a sua apresentação não estar organizada como uma edição de texto. Fica-se com a ideia de que, com outra ordenação, se poderia associar a esta obra uma importante mais-valia, que aumentaria substancialmente a utilidade. Aparentemente, não se perderia nada de relevante ao separar texto e seu aparato crítico do correspondente comentário, mas essa opção implicaria a extensão da crítica textual à parte descritiva e às coordenadas. No entanto, a esperança de em breve se publicar a anunciada edição da parte correspondente à Ibéria (p. 16) justifica que se mitigue a natureza crítica deste comentário.

No que respeita ao estabelecimento do texto, seria evitar, na minha perspectiva, a escolha de formas que não assentam na melhor tradição manuscrita. E ainda que, em alguns casos, se obtivessem lições divergentes das de outras fontes manifestamente mais fiáveis, seria preferível mantê-las, talvez porque os equívocos se devam situar já no próprio autor ou nas suas fontes de informação. Porque, na realidade, estamos perante duas coisas distintas e com autonomia: estabelecimento do texto ptolomaico com a maior fiabilidade possível e a determinação da formas onomásticas antigas, de acordo com a conjugação de todos os elementos disponíveis. Neste caso concreto, importa, acima de tudo, fixar o texto do geógrafo com todos os seus particularismos, incluindo os critérios da transliteração dos nomes hispâni- 
cos em grego, a sua acentuação ou equívocos na transcrição dos dados colhidos em outras fontes. Isso não invalida que, em sede de comentário, se confrontem as formas onomásticas de Ptolomeu com os de outras fontes com vista ao estabelecimento aproximativo da sua fonética original.

Neste sentido, estranha-se a preferência pela forma 'O $\lambda\llcorner\sigma \sigma i ́ \tau \omega v$ (p. 89), uma vez que essa forma não se encontra atestada em nenhum dos manuscritos primários. Parece-me que se justificaria a opção por 'O $\lambda$ ıoбí $\tau \omega v$ (unicamente regis-

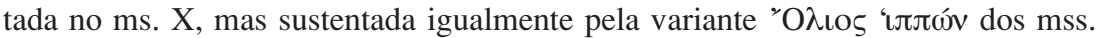
CARVW), embora se pudesse considerar, tal como o tinha feito Nobbe, a alterna-

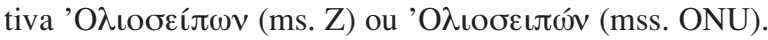

Um dos aspectos que releva do aparato crítico e desta fixação de texto é a importância do ms. X, representante de uma tradição com bastante autonomia, reflectida em abundantes formas únicas, muitas vezes constituídas como opção dos editores do texto. É o que acontece, só para dar alguns exemplos mais conhecidos,

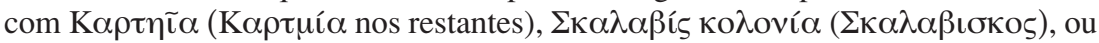
em П $\alpha \xi\llcorner o v \lambda i ́ \alpha$ ('A $\xi\llcorner o v \lambda i ́ \alpha)$. Neste último caso, porém, parece-me preferível manter a forma registada no ms. e não a separar em П $\alpha^{\prime} \xi$ 'Iov $\lambda i^{\alpha} \alpha$ (p. 93), por uma questão de princípio, mas também porque ela se justifica plenamente pela analogia

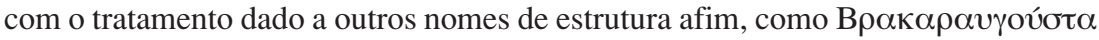

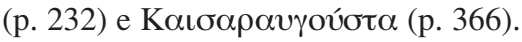

Porque este mesmo ms. "representa por sí solo una de las dos recensiones del arquetipo, es decir, casi cinquenta por ciento de la tradición" (p. 17), julgo que seria recomendável aceitar a lição deste mesmo códice para o discutido nome de um dos

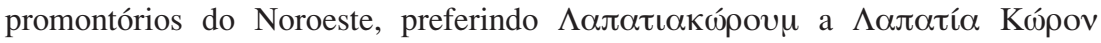
(p. 149), na sequência de uma pertinente sugestão de Monteagudo, de resto largamente seguida. A ela e em especial à sua interpretação linguística se refere amplamente o autor na análise etimológica deste passo (p. 150-152), considerando a sua proposta como "atractiva".

A tarefa de analisar criticamente as propostas de identificação de entidades e lugares referidos no texto ptolomaico constitui, como se declara expressamente na Introducción (p. 12), uma das finalidades desta obra. No entanto, o empenho que o autor colocou neste objectivo encontra-se muito aquém do que envolve a análise linguística desses vestígios onomásticos. Penso que a intenção de fornecer uma informação actualizada a respeito da localização de povos e lugares nem sempre foi conseguida, mesmo tendo em consideração que o trabalho académico que lhe deu origem tem mais de dez anos.

Entre as entradas que merecem reparos apresentam-se aqui apenas alguns exemplos, todos eles do ocidente peninsular, âmbito geográfico onde a informação do autor parecer ser mais deficitária, em parte devido ao enorme vazio que se regista na folha K-29 da Tabula Imperii Romani.

A respeito de Koגápvov, García Alonso chama justamente a atenção para a circunstância de este nome se relacionar com um dos municípios referidos na inscrição da ponte de Alcántara (CIL II, 760), os Colarni, o que, seguindo Hübner, implicaria a sua integração deste povo e da sua sede no conuentus Emeritensis 
(p. 115). Esta atribuição vaga deveria, no entanto, ser completada com os elementos que resultam de um terminus descoberto em Goujoim (Armamar, Viseu), com o qual se estabelece a fronteira entre esta entidade e os Arabrigenses (AE 1979, 331). Deste modo, evitar-se-ia que o nome correspondente fosse considerado entre os de localização incerta e deixasse, por isso, de figurar no mapa das localidades lusitanas (p. 442). A mesma epígrafe deveria implicar a deslocação de Arabriga para as margens do rio Douro, situação preferível a tomar esta ocorrência como correspondente à Ierabriga do Itinerário de Antonino, circunstância que parece estar na origem da posição que o autor lhe atribui, na sequência de Hübner e Tovar (p. 110). Para além de actualmente se recusar a identidade de ambas (ao contrário do que poderia acontecer com o geógrafo alexandrino), só esta última se situaria na zona ribeirinha do Tejo.

Ainda sobre as ocorrências registadas nesse mesmo mapa, parece que não há qualquer elemento minimamente consistente que justifique a localização de Lauare, pelo que este nome deveria passar, na minha perspectiva, para a lista dos de atribuição geográfica incerta. A opção de J. L. García Alonso decorre certamente da aceitação de uma proposta de Müller, segundo a qual se poderia aproximar este topónimo de uma ciuitas Auar(orum), de um grupo Auarorum e de uma indicação de origo a que se atribui a forma Auarus (p. 102). Estas ocorrências, na realidade, devem ser corrigidas respectivamente para ciuitas Arauorum (CIL II, 429 e AE 1952, 109), Araui (CIL II, 760) e Araus (CIL II, 502 e 1017) ou Arauus ${ }^{1}$, tornando-se muito mais complicado admitir uma associação destes nomes à problemática Lauare.

Entre os Vetões se integra uma das cidades designadas como 'Окє (p. 121-122), para a qual considera, dubitativamente, uma equivalência com a moderna Saucelle (Zamora), aceitando a correspondência com Ocelo Duri (ITIN. ANT. 434,6). Penso, ao contrário do autor, que os argumentos já sustentados por M. L. Albertos e, inclusivamente, que deveria ser aceite a possibilidade, por ela admitida, de se relacionar a cidade vetónica com o epíteto Ocelaecus / Ocelaeca registado na epígrafe de Ferro $^{2}$, tal como alguns autores têm sublinhado ${ }^{3}$, apesar dos grandes problemas que ainda subsistem sobre a identificação concreta do seu território. De qualquer modo, não creio que possam restar dúvidas sobre uma localização desta entidade em território mais meridional, a par dos Lancienses.

A existência, para além de Arucci, da nova ciuitas Arucitana (p. 76), que supostamente se documentaria numa inscrição de Moura dificilmente se pode aceitar,

1 S. Haba Quirós. Medellín romano: La colonia Metellinensis y su territorio. Badajoz. 1998 , p. $95-96$, n. 6.

2 A propósito de algunas divinidades lusitanas, Symbolae Ludovico Mitxelena septuagenario oblatae, Pars prior. Vitoria, 1985, p. 470-471, 473

3 Ultimamente em J. de Alarcão, Novas perspectivas sobre os Lusitanos (e outros mundos), Revista Portuguesa de Arqueologia. 4(2), 2001, esp. p. 295-304. 
pelo menos após a interpretação proposta por J. d'Encarnação 4 para a epígrafe em questão, unanimemente aceite.

Ainda que se aceitasse a problemática identidade entre os Aobrigenses referidos no Padrão dos Povos (CIL II, 5616) e o oppidum Abobrica reportado num passo pliniano (PLIN. nat. 4, 112), em nenhum momento se diz que esta localidade integraria o território dos Cileni, como se sugere com a expressão Abobrica Cilenorum, atribuída ao naturalista (p. 130). De resto, se alguma ilação parece resultar do texto referido é precisamente a circunstância desse povoado não se integrar no território desta entidade do conuentus Lucensis, porque dessa passagem decorre a sua ligação ao conuentus Bracarum. Neste caso, a informação de Plínio só poderia ser eventualmente usada, extrapolando um pouco, para justificar vínculo da cidade aos Heleni ou Grouii ${ }^{5}$.

A análise linguística constitui, sem dúvida, a vertente mais importante desta obra e aquela em que são mais significativos os novos contributos. E é no domínio das propostas etimológicas que as novidades se fazem notar de forma mais evidente. Penso, de qualquer modo, que teria valido a pena chamar a atenção para as dificuldades que se colocam com particular acuidade na interpretação de um repertório onomástico, essencialmente constituído por topónimos e etnónimos. Falta, neste tipo de materiais, a fundamentação de natureza semântica que permitiria dar consistência às propostas de etimologia sugeridas. Deste modo, fica-se com a sensação de que qualquer explicação foneticamente viável ganha igual validade, dado que a pertinência semântica das diferentes opções se coloca, à partida, no mesmo plano.

Por essa razão, se apresentam, com frequência, múltiplas possibilidades interpretativas para o mesmo nome, em especial quando o nosso desconhecimento a seu respeito aumenta consideravelmente, sem que haja condições para decidir sobre a sua validade. A título de exemplo, vejam-se as diferentes propostas para o

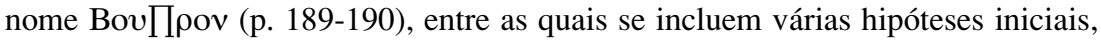
respectivamente a base céltica *bou- «vaca»; uma formação em - $r$ - a partir de "la raíz indoeuropea *bhou, *bhu «crecer, prosperar»; e o "el antiguo europeo /.../ *uer- *ur (ai. var «agua», avéstico var «lluvia»)". Se este nome tem algo que ver com o antigo topónimo da Britânia Burrium, como admite, poder-se-á considerar ainda a interpretação dada por Jackson, Rivet e Smith ("com una base *burro- que traducen por «stout, study, big») e a possibilidade de se poder aproximar de «una serie de nombres que comienzan por bor $(r)$-, bors-" para os quais D. Ellis Evans sugeriu uma relação "con el adjetivo irlandés medio borr, «puffed, bloated, proud»" e com outros termos afins das antigas línguas insulares. Enumeram-se, pois, cinco hipóteses plausíveis, sem que se configure um argumento que leve a optar por uma delas.

4 Uma homenagem a Agripina, mulher de Germânico. Conimbriga. 28 1989, p. 162-164.

5 Tabula Imperii Romani: Hoja K-29, p. 19, 45, 59-69. 
Por outro lado, uma das linhas seguidas por esta análise é a de apontar paralelos onomásticos, preferencialmente na documentação relativa às antigas línguas da Europa, em particular às de âmbito ocidental. Neste caso concreto, apontam-se especificamente NNL, NNP e NNE da Hispânia, Itália, Dalmácia e, como se viu, das Ilhas Britânicas, denotando um diversidade geográfica assinalável. Seria interessante, nesta perspectiva, que se acrescentasse um significativo contributo neste domínio, atestado numa região próxima, na epígrafe votiva dedicada Laribus Buricis (AE 1973, 320; AE 1974, 391), originária precisamente do concelho de Terras do Bouro (Braga), localidade que conservou exemplarmente os vestígios do antigo topónimo.

Aparentemente, o objectivo destes exercícios de hipóteses e de busca de possíveis paralelos consiste, em última análise, em proporcionar elementos para uma integração das realidades linguísticas em determinado âmbito, quer conferindo alguma consistência à sua classificação dentro das línguas célticas, do lusitano ou do "antiguo europeo" quer, em outros casos, visando decidir, mais simplesmente, acerca da sua inclusão ou não no âmbito das línguas indo-europeias.

Deste modo se compreende o amplo capítulo que recebe o nome de Conclusiones, onde se procede, por assim dizer, a uma análise de conjunto do largo repertório e das considerações que a seu respeito se teceram. Por esta via se pretende analisar, tendo como base a separação de natureza étnica operada pelo próprio Ptolomeu, cada um dos núcleos onomásticos, procurando primeiro a sua caracterização linguística, mas não esquecendo as relações desta vertente com o domínio cultural.

Uma das dificuldades principais destas tarefas reside precisamente nos critérios pelos quais se faz a integração dos nomes. A evidente falta de conhecimentos que a investigação afronta reflecte-se de forma aguda nos resultados a que chega José Luís García Alonso, em especial no modo como os resultados da classificação se exprimem. $\mathrm{O}$ autor expressa graficamente as dúvidas a esse respeito através de um sistema de pontos de interrogação, que leva a que estes aumentem em número (de um a quatro) em função das dúvidas que lhe coloca determinada integração. As muitas incertezas levam a que, com frequência, o mesmo nome possa aparecer classificado em várias categorias e, em casos extremos, em quase todas elas. É o que acontece, por exemplo, com o hidrónimo Tagus (p. 441-442), que se encontra nos nomes "antiguo europeos", célticos e «otros nomes indoeuropeos (¿lusitanos?)».

Perguntamo-nos se, no estado actual dos nossos conhecimentos, este procedimento de propor a qualquer título uma integração não será contraproducente e se não se revelaria mais correcto, em particular nos casos em que as dúvidas são manifestas (a percentagem de exemplos com três e quatro pontos de interrogação é considerável), optar pura e simplesmente por os omitir numa classificação deste tipo. Também a terminologia usada reflecte as múltiplas hesitações do autor (e da investigação) a respeito da integração linguística dos topónimos. Posta de lado a questão da pertinência ou não de expressões como "antiguo europeo", sobre o qual existe já ampla bibliografia, alguma especialmente concernente ao âmbito hispânico, suscita-me algumas interrogações a utilização do termo "lusitano" e sobretudo "lusitanoide" para classificar alguns nomes, não apenas do ocidente hispânico, 
mas genericamente de toda a península (carpetanos, p. 498; ástures, p. 454; turdetanos, p. 432; túrdulos, p. 434), mas aparentemente nenhum entre os galaicos brácaros e vetões, as entidades que mantêm mais afinidades com os lusitanos. Dado o estado incipiente do conhecimento relativo a essa língua ocidental interrogamo-nos sobre os fundamentos dessas classificações.

A comparação dos resultados obtidos não deixa, na minha perspectiva, de ser esclarecedora e, em alguns casos, surpreendente.

Esclarecedora, por exemplo, no caso dos Turdetanos. Não tanto pelo facto de aí se registar uma percentagem significativa de nomes que, com alguma segurança, a maior parte dos investigadores considera não-indo-europeus (o autor usa com frequência a expressão "lengua tartesia", mas aparentemente não aplicada a todos esses elementos, mais genericamente classificados como "sudoccidentales" p. 432), mas também pela presença marcante de nomes célticos, em consonância com elementos que são proporcionados por outro tipo de dados, nomeadamente as informações de natureza histórica que as fontes transmitem. Com a designação de «turdetanos» se qualificam, por exemplo, nomes que em Plínio (nat. 3, 14) se atribuem aos célticos da Bética (Seria, Nertobriga, Contributa) ou aos túrdulos (Mirobriga, Arsa). Quer isto dizer, portanto, que não se pode atribuir ao quadro étnico traçado por Ptolomeu um significado que ele não possui, nomeadamente conjecturar a partir dele uma certa coerência linguística e cultural num determinado período.

Por outro lado, considero a comparação de resultados surpreendente no que respeita aos resultados que algumas áreas apresentam. $\mathrm{O}$ mundo galaico, em especial o bracarense, revela uma particular abundância de nomes classificados como célticos, boa parte deles sem qualquer hesitação, a par de uma percentagem pouco relevante de qualquer uma das outras categorias, à excepção dos nomes latinos e alguns “antiguo-europeos". Depois de sublinhar, nas considerações prévias à análise do conjunto (p. 448), a tradicional opção da maioria dos investigadores pela natureza não-céltica da língua falada pelos Galaicos, García Alonso considera, perante os dados onomásticos, que a situação acima aludida se deve explicar por uma migração de populações célticas para os territórios ocidentais, a partir da Celtibéria. Esta explicação não deixa de causar alguma perplexidade a quem confrontar a realidade da Galécia com a da Celtibéria (p. 500-502), onde apenas se dão como seguramente célticos Belisarium, Nertobriga, Arcobriga, Mediolon, Segobriga e Laxta, sendo um número significativo de nomes integrado nesse grupo sem provas suficientes (p. 502). Julgo ser necessário encontrar outras explicações para o fenómeno que, diga-se, não se manifesta apenas neste aspecto particular, mas atinge do mesmo modo outros domínios. Para falar de um dos aspectos mais conhecidos e ao mesmo tempo menos problemáticos do ponto de vista linguístico, basta analisar a dispersão dos nomes em -bris / -briga unanimemente considerados de natureza céltica, para constatar que a concentração destes topónimos é particularmente evidente no mundo galaico e na Lusitânia setentrional, mas a sua presença quase residual na Celtibéria. E penso que não será muito ousado pretender que esta mesma situação se repita em muitos outros exemplos. 
Sobre esta questão, parece claro que o autor partiu para a análise com um pressuposto de base, já consolidado, havendo que encontrar explicações para tudo o que não se enquadra nele.

Se, por um lado, esta obra se preocupa com a análise das componentes lexicais do repertório onomástico ptolomaico, por outro confere pouca atenção, na minha perspectiva, à formação das palavras e, em especial, aos elementos sufixais. Penso que seria de toda a utilidade ter uma visão de conjunto a respeito dos formantes deste vasto corpus e certamente dela poderiam resultar interessantes conclusões. Para tal haveria, desde logo, que ultrapassar a visão compartimentada que a estrutura da Geografia apresenta, de forma a que, na formulação das principais ilações, se tivessem em conta basicamente critérios de natureza linguística, sem a limitação imposta por divisões "étnicas" cuja pertinência é, no mínimo, pouco clara.

De qualquer modo, estas observações não podem diminuir os enormes méritos desta publicação. Revelando sempre uma grande preocupação com o rigor, o autor busca uma base o mais sólida possível e faz incidir sobre ela uma análise linguística que, em muitos aspectos, constituirá uma referência para a investigação futura. Apesar de alguns riscos inerentes, a multiplicidade de propostas etimológicas apresenta a vantagem de, com frequência, contrapor às propostas já conhecidas, outras que se afiguram com igual ou maior credibilidade. Integrando-se na atenção crescente que as línguas paleo-hispânicas têm despertado, este trabalho representa um passo decisivo neste domínio e ele próprio constituirá, certamente, um incentivo e um exemplo para as gerações mais jovens.

Amílcar Guerra 